\title{
Metaphors for medicine: revealing reflections or just popular parodies?
}

Deborah Kirklin Royal Free E University College Medical School, London

“، . . .before you get spoilt by it all. Before you become a fully qualified doctor, just give me a helping hand as a human being.' (Kostoglotov: cancer patient)" 1

Are human beings irreversibly "spoilt" by medical training or merely disengaged from "normal" human interaction? If what is desired is a doctor who reaches out as a human being to his or her patients then it is important for educators to know why that sometimes fails to happen. Is the end product of medical training (sometimes) incapable of stretching out its hand or instead just disinclined to do so? If the latter, then presumably we should focus our energies on motivating practitioners to reach out by, for example, inspiring empathy. If, however, medical culture imposes physical or psychological constraints on practitioners then it is our very conception of medicine, reflected in the training process, and its potential to spoil the human beings it turns into doctors that should be the subject of our concern.

Physician-centred and physician-generated literature, involving respectively tales of doctors or tales by doctors, plays a prominent role in much of medical humanities teaching. This genre has always been enjoyed both by the public and by doctors and constitutes a rich teaching resource both at undergraduate and postgraduate level as well as in continuing medical education. Close examination of the characters portrayed can, for example, provide an interesting and important opportunity to reflect on the differences between public expectations of, and ideas about, doctors, and their own understanding of what their role will and should be. If, however, as Berger argues, medicine is a social phenomenon-far more than the sum of the individuals concerned-then reference to the adequate or even the ideal doctor can only begin to answer the question "what is or should medicine be?". ${ }^{2}$ If popular culture is to help us in our search for a deeper understanding of this phenomenon then we could do worse than look for guidance to the metaphors used about medicine, that is about its culture, practice and practitioners.

Life and death are recurrent themes in popular culture and related metaphors abound. Phil Barker has suggested that metaphors are so widely used in relation to life and death because "Life is so real I can meaningfully represent it only in metaphor" ${ }^{3}$ and that analysis of these metaphors acts as a guide to what matters most to those using them. If the same is true of medicine, our attempts to understand what matters most in medicine might be helped by analysis of the medical metaphors found in the arts. Susan Sontag argues that the metaphors used by a society to do this reveal much about the belief systems of the society as well as about the taboos and anxieties related to the condition. ${ }^{4}$ It is tempting to think that an examination of the metaphors and characterisations used to portray doctors and the practice of medicine might reveal much about the culturally perceived strengths, weaknesses and flaws of medicine. These are key issues which should take centre stage as the emerging field of medical humanities stakes out its intellectual territory.

Glasser describes a course designed to allow students the opportunity to reflect on cultural representations of medicine and doctors. ${ }^{5}$ Exploration of these representations provides an opportunity to examine the tensions inherent in the doctor's role. Engagement with society's metaphors for medicine can facilitate a clearer understanding about what medicine is and, perhaps more importantly, what it could and should be. If courses like Glasser's inspire tomorrow's doctors to gaze steadily and open-mindedly at the reflected images then they deserve both recognition and support.

Deborah Kirklin is Pfizer Lecturer in Medical Humanities and co-directs the Centre for Medical Humanities, Address for correspondence: Centre for Medical Humanities, Department of Primary Care $\mathcal{E}$ Population Sciences, Royal Free E U University College Medical School, Highgate Hill, London N19 5LW. Email:d.kirklin@pcps.ucl.ac.uk

\section{References}

1 Solzhenitsyn A. Cancer ward. London: Penguin, 1971: 40

$2 \mathrm{http}: / /$ endeavor.med.nyu.edu/lit-med

3 Some feel empathy can be successfully enhanced by education. For example Kirklin D, Meakin R, Singh S, Lloyd M. Living with and dying from cancer: a humanities special study module. fournal of Medical Ethics: Medical Humanities 2000;26:51-4.

4 Others have serious reservations about the production of 4 Others have serious reservations about the production of erature in medical education. A commentary on the poem: Roswell, Hanger 84. Fournal of Medical Ethics 1999;25:529-31. 5 Berger J, Mohr J. A fortunate man: the story of a country doctor. Middlesex; Penguin, 1967

6 Barker P. Working with the metaphors of life and death. In: Kirklin D, Richardson R, eds. Medical humanities: a practical introduction. London: Royal College of Physicians, 2001.

7 Sontag S. Illness as metaphor. London: Allen Lane, 1979.

8 Glasser B. From Kafka to Casualty: doctors and medicine in popular culture and the arts-a special studies module. Fournal of Medical Ethics: Medical Humanities 2001;27:99-101. 